\title{
Numerical and experimental study of bursting prediction in tube hydroforming of Al 7020-T6
}

\author{
Arvand Afshar, Ramin Hashemi*, Reza Madoliat, Davood Rahmatabadi, and Behzad Hadiyan \\ School of Mechanical Engineering, Iran University of Science and Technology, Tehran, Iran
}

Received: 24 November 2016 / Accepted: 6 March 2017

\begin{abstract}
In this study, forming limit diagram (FLD) of tubular material (Al 7020-T6) was determined numerically and experimentally. A set of experimental bulge tests were carried out to determine FLD under combined internal pressure and axial feeding. Also, a numerical approach which is based on the acceleration of plastic strain (i.e., the second derivation) was applied to compute the hydroforming strain limit diagram. Based on this method, the localized necking would be started when the acceleration of the max plastic strain got its maximum value. Finally, the numerical FLD was verified by experimental test results on the aluminum tube 7020-T6 and a good agreement between the proposed method and the experimental works was observed.
\end{abstract}

Keywords: tube hydroforming / bursting / second derivative of strain / forming limit diagram / experiment

\section{Introduction}

Forming limit diagram (FLD) is a significant criterion for evaluating formability of tubular materials, which is commonly obtained from theoretical calculations, finite element simulation and experiment. Hydroforming process makes integrated tubular parts with high ratio of strengthto-weight in one step. By applying oil pressure into the tube, and applying axial force to the ends, a tubular blank is formed into the internal shape of the die. In this process, the original specimen is a simple tube (direct or bend tube). Due to increasing requests for light-weight parts, hydroforming processes have been widely used to produce and make parts in various fields, such as automobile, aircraft, aerospace, and shipbuilding industries [1]. Hashemi et al. [1] have also considered tube hydroforming process, including the manufacturing of metal bellows.. Asnafi and Skogsgårdh [2] proposed a mathematical model to predict the forming pressure and the related feeding distance required to hydroform a circular tube into a $\mathrm{T}$ shape product without wrinkling and bursting. The use of aluminum alloys in the place of steel components in automotive applications saw a significant increase during the last few years. For this reason, hydroforming of aluminum tubes is a very desirable manufacturing process instead of sheet metal forming. In tube hydroforming, it is required that the vacant tube should be formed into a die cavity of the final shape without any kind of deficiency such

\footnotetext{
* e-mail: rhashemi@iust.ac.ir
}

as bursting, wrinkling or buckling. Since bursting is an impression of localized necking which is a condition of local instability under excessive tensile stresses, prediction of necking is an important problem before designing the details of processes [3]. FLDs are appointed to determine the tubular materials formability. The laboratory test results showed that the FLDs are influenced by several parameters including the strain rate [4], strain hardening and anisotropy coefficients [5], heat treatment [6], grain size [7] and strain path changes [8]. After obtaining the forming limit curves (FLCs) by Keeler and Backofen [9], many researchers tried to develop some numerical and analytical models to determine the sheet metal formability. But, only a little attention has been paid to study the behavior of tubular materials. For example, Kim et al. [10] predicted the bursting failure in tube hydroforming considering plastic anisotropy by using numerical calculations. Song et al. [11] used analytical approach to bursting in tube hydroforming using diffuse plastic instability. One year later, the team combined the two previous methods: analytical and numerical methods for prediction of forming limit in tube hydroforming [12]. Hwang et al. [13] predicted FLDs of tubular materials by bulge tests in two ways. They have used the Hill's law for calculations and did bulge tests for an experiment and then compared the two methods together. Chen et al. [14] used thickness gradient criterion for seamed tube hydroforming that resulting in FLD. They validated numerical solution with experimental work. Seyedkashi et al. [15] analyzed two-layered tube hydroforming with analytical and experimental verification. 


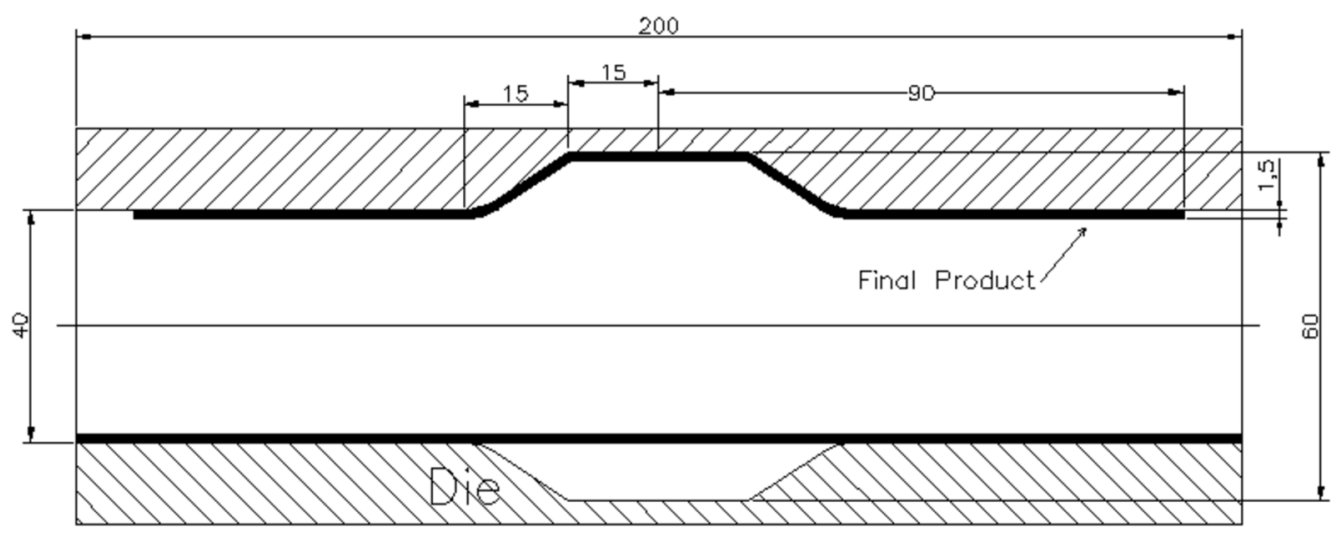

Fig. 1. Dimensions and configurations of an initial tube and its final bulged part (mm).

Table 1. The material and mechanical properties of aluminum tube 7020-T6.

\begin{tabular}{llllll}
\hline Material & $\begin{array}{l}\text { Specific } \\
\text { gravity }\left(\mathrm{kg} \mathrm{m}^{-3}\right)\end{array}$ & $\begin{array}{l}\text { Young module, } \\
E(\mathrm{GPa})\end{array}$ & $\begin{array}{l}\text { Yield strength, } \\
\text { YS }(\mathrm{MPa})\end{array}$ & $\begin{array}{l}\text { Strength coefficient, } \\
K(\mathrm{MPa})\end{array}$ & $\begin{array}{l}\text { Strain hardening } \\
\text { index, } n\end{array}$ \\
\hline Al7020-T6 & 2780 & 71 & 305 & 370 & 0.17 \\
\hline
\end{tabular}

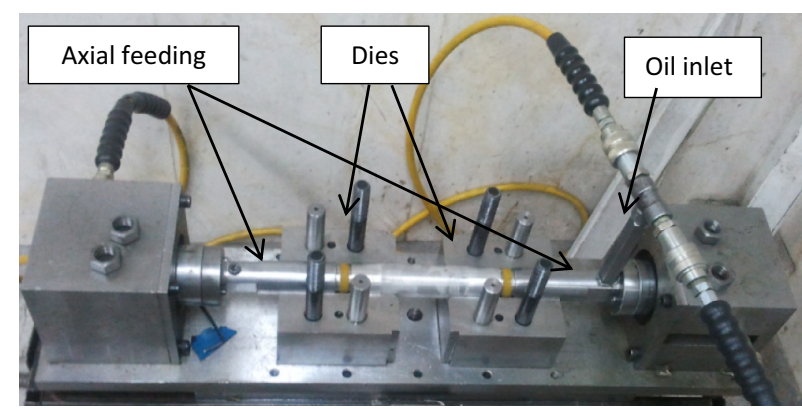

Fig. 2. Free bulge setup.

Loading Path

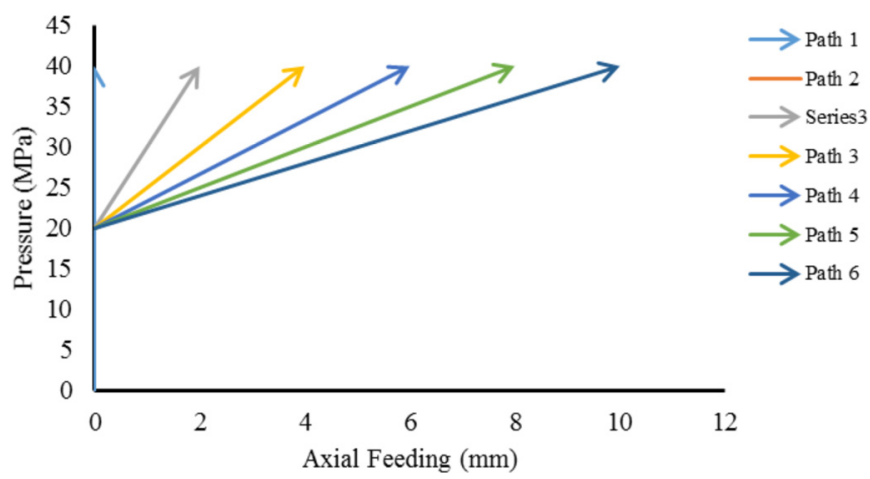

Fig. 3. The input loading paths with a combination of internal pressure and axial feeding.

In this paper, FLCs of tubular materials (Al 7020-T6) with respect to axial feeding and hydraulic pressure were determined numerically and experimentally for the first time. The computed FLD was verified by a series of experimental bulge tests. A numerical approach was applied to FLC prediction. This numerical method is

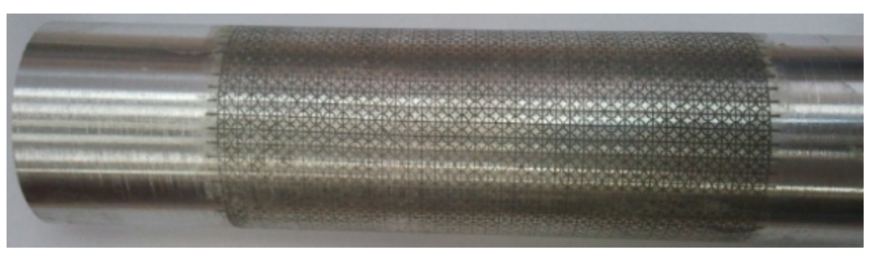

Fig. 4. Circles engraved on the tube.

based on the acceleration of plastic strain (i.e., the second derivation) which was applied to determine the onset of necking for tube materials. Based on this method, the localized necking would be started when the acceleration of the max plastic strain gets its maximum value.

\section{Experimental work}

\subsection{Tube bulging test}

The dimensions and configurations of an initial tube and its final bulged part are shown in Figure 1. The outer diameter of the pipe was $40 \mathrm{~mm}$ and the initial thickness of the tubular blank was $1.5 \mathrm{~mm}$. Aluminum pipes were seamless and produced by extrusion process.

The mechanical and material properties of the tube were determined by standard test using specimen, which were prepared according to ASTM-E8 specification at a constant crosshead speed of $2 \mathrm{~mm} \mathrm{~min}^{-1}$. The mechanical and material properties are presented in Table 1.

To evaluate the hydroforming limit strain diagram, a series of bulge tests were carried out on aluminum tube 7020-T6. For doing the tests, an experimental setup with the ability to control internal pressure and axial feeding was provided. This setup had two hydraulic jacks and a hydraulic pump and it is shown in Figure 2. All hydraulic instruments used in the experimental procedure, including 


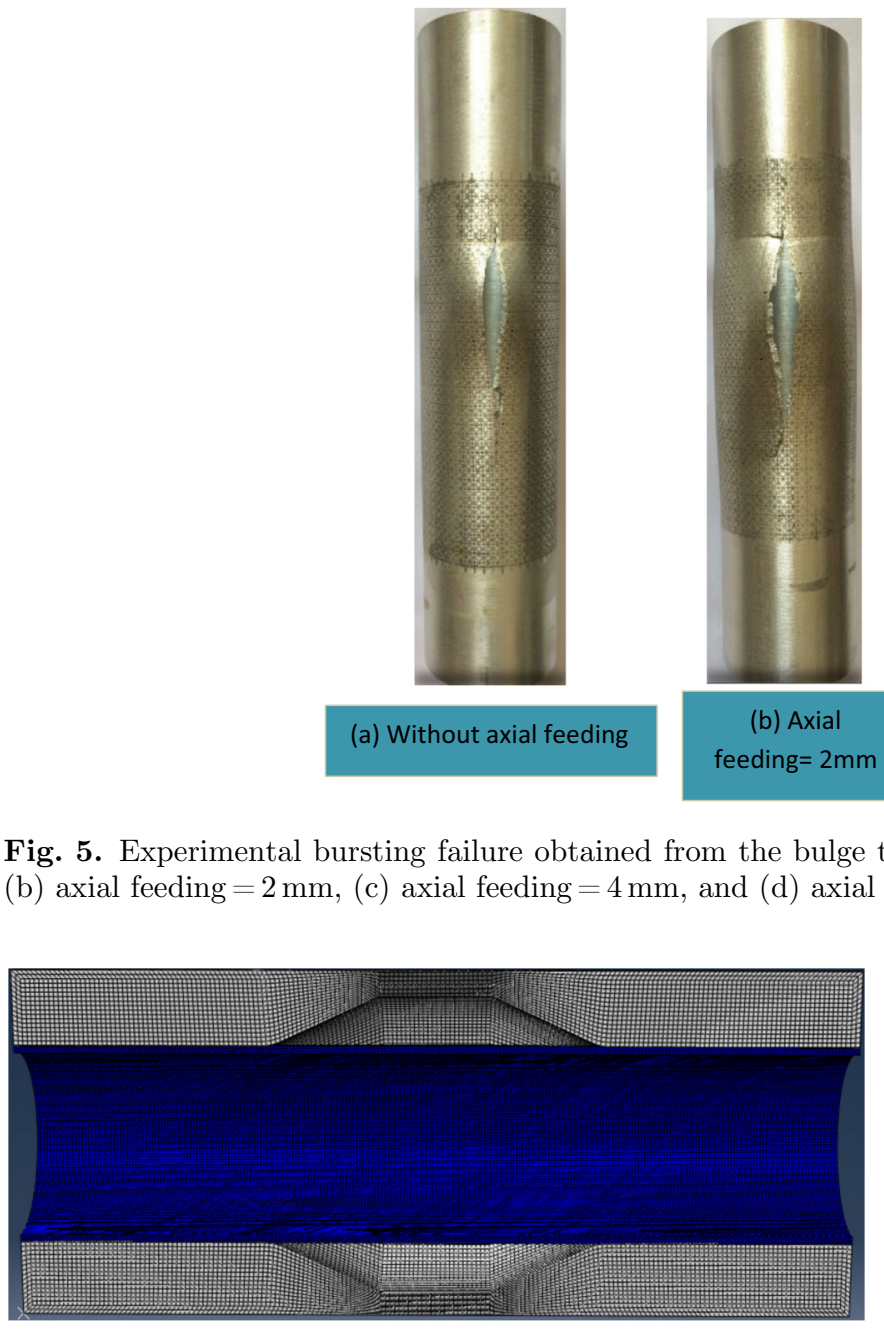

Fig. 6. Finite element simulation model.

pumps and valves were fabricated in the Enerpac company (the supplier's name was Enerpac). The measurement accuracy of hydraulic pump was up to 1 bar. The two ends of the tube were free to be able to move in the axial direction for providing axial feeding. Internal pressure measured by barometer and axial feeding measured by linear variable differential transformer with the measurement accuracy of $0.01 \mathrm{~mm}$. be applied to the tube. For this purpose, the linear loading curves from internal pressure and axial feeding were used. The six applied load paths are shown in Figure 3. Loads were applied in two steps, initially the internal pressure was increased and then the axial feeding was applied, till a burst occurred in the tube. The internal pressure and the axial feeding displacements (e.g., the input loading paths) shown in Figure 3 which were controlled by the PC-based controller of the experimental setup for a series of the bulging tests. For measuring strains in the experimental work, a regular grid layout of the circle with a diameter of $2.5 \mathrm{~mm}$ on the samples was etched. To carve these circles, electrochemical etching device was used.
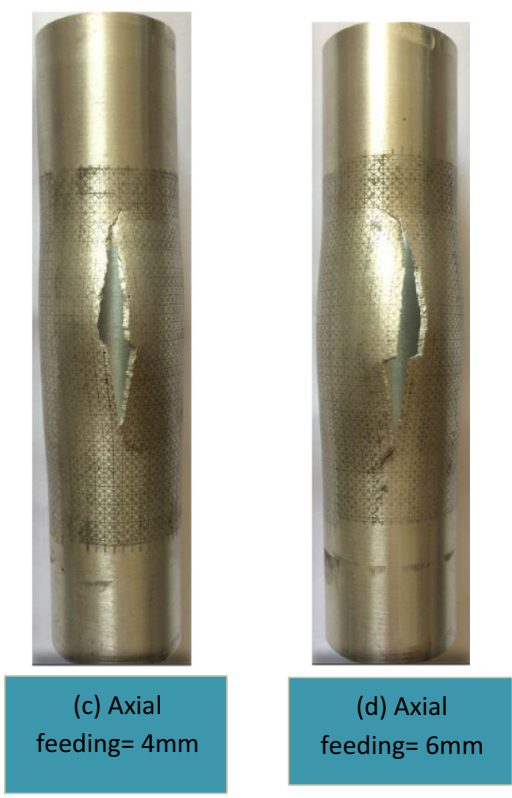

Fig. 5. Experimental bursting failure obtained from the bulge tests under the different loading paths: (a) without axial feeding,

To obtain the FLCs, different loading paths with a combination of internal pressure and axial feeding should

The circles engraved on the tube were shown in Figure 4. After examination of the bulge tests, the circles transformed to ellipses after deformation. The major and minor diameters of the ellipses were measured using a profile projector machine.

As a result of excessive pressurizing during the bulge process, bursting occurred in the middle of the tube wall as illustrated in Figure 5.

To determine hydroforming strain limit diagram experimentally, at first, the tubes were carved and then placed under loadings. Loadings stopped when the tube burst occurred. After the bursting, the major and minor diameters of the ellipses near the crack were measured and then the limit strains were calculated. The major and minor engineering strains can be obtained from the following equations. Measuring diameters were performed by using the profile projector machine.

$$
\begin{aligned}
& e_{1}=\frac{a-d}{d} \\
& e_{2}=\frac{b-d}{d}
\end{aligned}
$$

In these equations, " $a$ " is the large diameter of ellipse and " $b$ " is the small diameter of it. " $d$ " is the diameter carved in advance.

\section{Finite element modeling}

The ABAQUS/Explicit FE software was used to model the hydroforming process in order to investigate the FLDs of aluminum tubes. All the analyses were realized using an explicit finite element approach. The die map used in the simulation can be seen in Figure 1. 


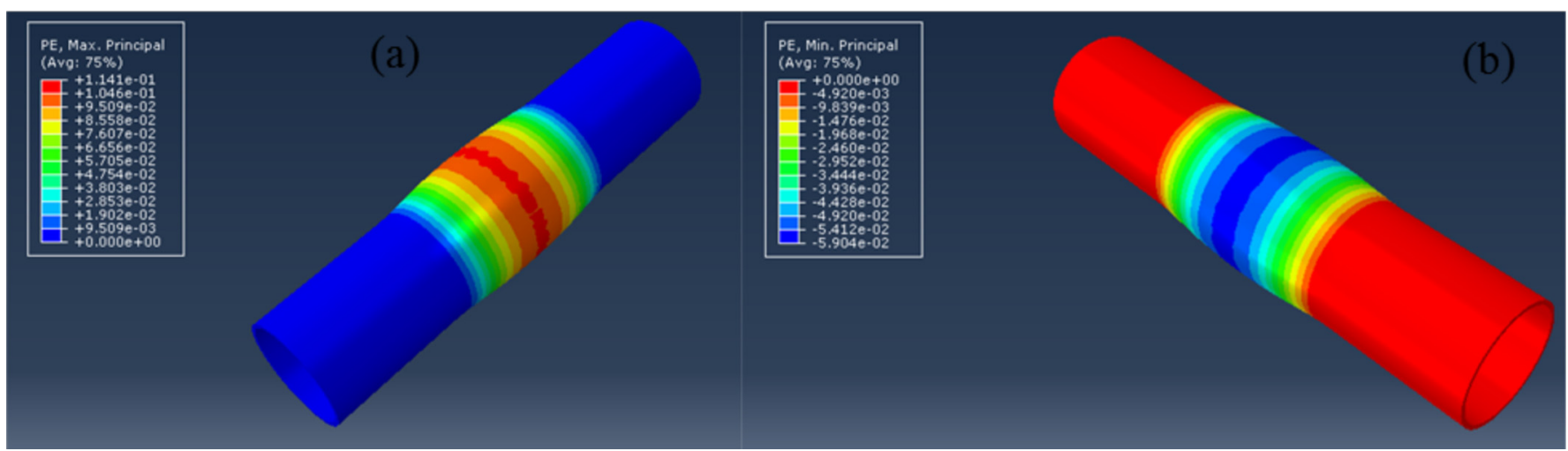

Fig. 7. Strain distributions for $4 \mathrm{~mm}$ axial feeding: (a) max strain and (b) min strain.

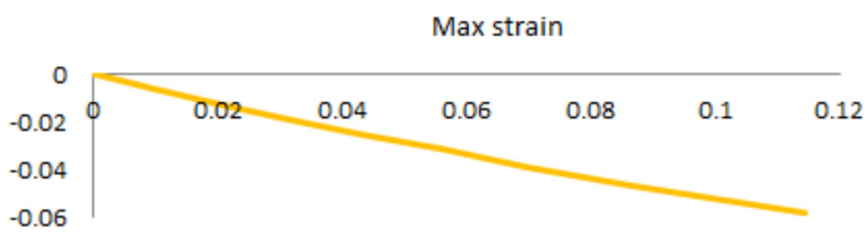

Min strain

Fig. 8. The relationship between the two criteria large strain and small strain.

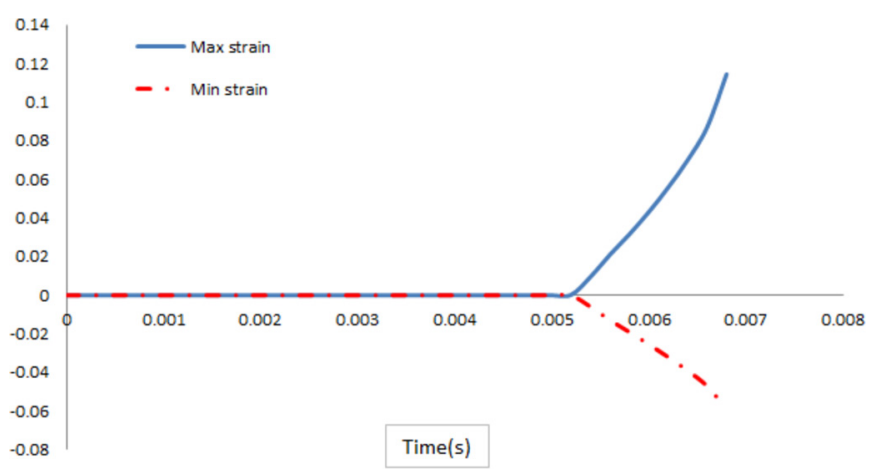

Fig. 9. The highest and lowest strain versus time for plane strain mode.

This process was simulated with the solving dynamic/ explicit. Material properties were extracted with use of uniaxial tensile tests and were entered in the relevant module. Penalty method was used to establish contact between the tube and mold. Anisotropy coefficients for that material, by the simple tensile test were measured in different directions. To apply anisotropy into the simulation, the Hill's 48-yield criterion [16] was used. Hill's 48yield criterion and its coefficients based on the measured anisotropy in the directions of 0,45 and 90 in equations (3)(7) is given.

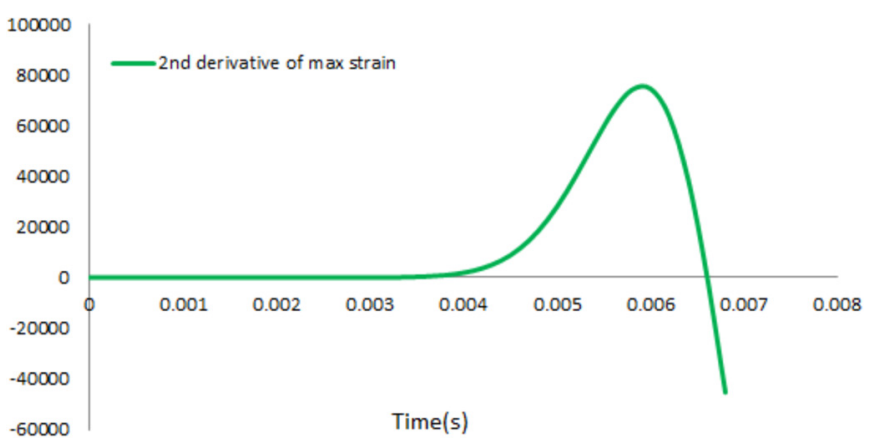

Fig. 10. The second derivative of max strain for $4 \mathrm{~mm}$ axial feeding.

$$
\begin{gathered}
\text { see equation (3) below } \\
H=\frac{r_{0}}{1+r_{0}} \\
F=\frac{H}{r_{90}} \\
G=\frac{H}{r_{0}} \\
N=\frac{\left(r_{90}+r_{0}\right)\left(2 r_{45}+1\right)}{2 r_{90}\left(1+r_{0}\right)}
\end{gathered}
$$

The coefficients of Hill's 48-yield criterion for a threedimensional stress mode and its relation with the main factors yield criterion are given below.

$$
F=\frac{1}{2}\left(\frac{1}{R_{22}^{2}}+\frac{1}{R_{33}^{2}}-\frac{1}{R_{11}^{2}}\right)
$$

$$
f_{(\sigma)}=\sqrt{F\left(\sigma_{22}-\sigma_{33}\right)^{2}+G\left(\sigma_{33}-\sigma_{11}\right)^{2}+H\left(\sigma_{11}-\sigma_{22}\right)^{2}+2 L \sigma_{23}{ }^{2}+2 M \sigma_{31}^{2}+2 N \sigma_{12}{ }^{2}}
$$




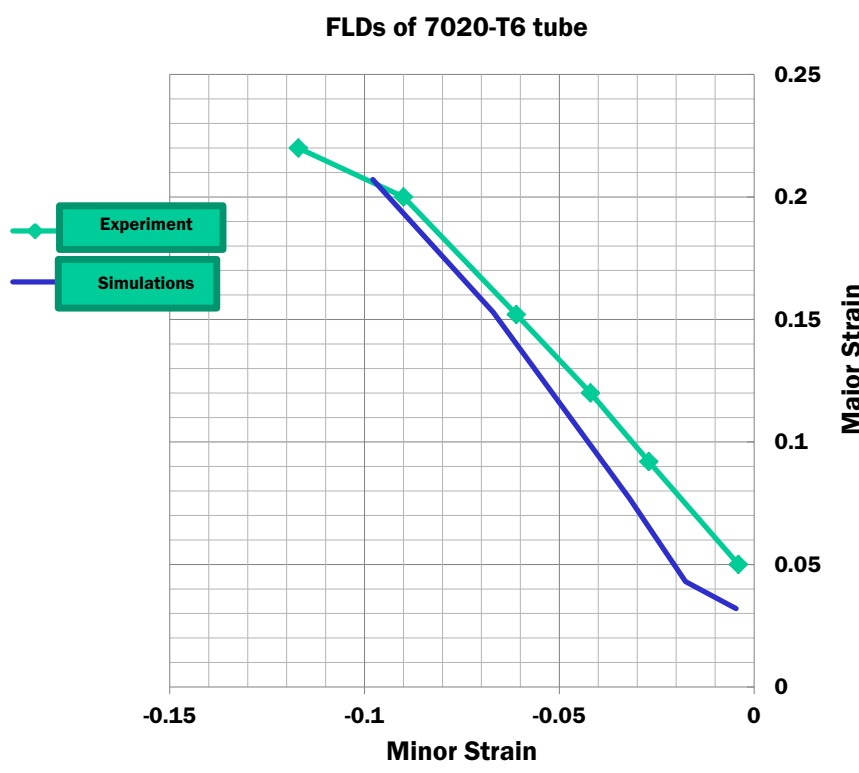

Fig. 11. The FLDs for the aluminum tube 7020-T6.

$$
\begin{gathered}
G=\frac{1}{2}\left(\frac{1}{R_{33}{ }^{2}}+\frac{1}{R_{11}^{2}}-\frac{1}{R_{22}{ }^{2}}\right) \\
H=\frac{1}{2}\left(\frac{1}{R_{11}^{2}}+\frac{1}{R_{22}^{2}}-\frac{1}{R_{33}^{2}}\right) \\
L=\frac{3}{2 R_{23}^{2}} \\
M=\frac{3}{2 R_{13}^{2}} \\
N=\frac{3}{2 R_{12}^{2}}
\end{gathered}
$$

In this paper, for convenience, a Cartesian coordinate system changed to the cylindrical that, in which case, the anisotropy factor for the thickness and the other directions were put " 1 ".

The tube was considered as a deformable part and it was meshed using composite shell elements (four nodes, reduced integration elements, ABAQUS type S4R). Friction between the mold and the tube was intended 0.1 . The tube was used in the power hardening law to model its behavior. The Holloman's equation is written as follows [17]:

$$
\bar{\sigma}_{Y}=K(\bar{\varepsilon})^{n}
$$

where $\bar{\sigma}_{Y}$ is the effective stress, $\bar{\varepsilon}$ is the effective plastic strain, $n$ is strain hardening exponent and $K$ is the strength coefficient.

Figure 6 demonstrates the FE model included of the tube and the die.
Table 2. Comparison of the experimental and numerical major strains for two different strain paths.

\begin{tabular}{lll}
\hline & $\begin{array}{l}\text { Near plane } \\
\text { strain mode }\end{array}$ & $\begin{array}{l}\text { Near uniaxial } \\
\text { tension mode }\end{array}$ \\
\hline Experiment & 0.05 & 0.21 \\
FEM & 0.03 & 0.20 \\
\hline
\end{tabular}

\subsection{Analytical necking criterion}

Selecting an appropriate necking criterion is important to determine the start of plastic instability in tube hydroforming. For obtaining the FLC, in this research, necking criteria, containing the acceleration of maximum and minimum strain were employed to predict the onset of plastic instability.

The necking time of a specimen could be determined by using this method. To obtain the FLC numerically, it was essential to predict at which time and where the necking phenomena occurred in the analyzed material. It was possible to predict the necking time of the analyzed specimen using its acceleration of the max strain. Two different criteria to detect the start of plastic instability in the tube were suggested to determine the FLC. The forming limits of the tube were predicted, considering the history of the maximum and minimum strains by taking the maximum second derivative. For a given strain path, the limit strain was determined at the maximum value of the strain acceleration. Figure 7 represents the maximum and minimum strains for the $4 \mathrm{~mm}$ axial feeding mode (Fig. 3).

Figure 8 shows a relationship between the two criteria large strain and small strain. Due to the linear relationship between the two criteria, it is concluded that the second derivative both at the same time reaches its maximum value. As a result, the use of either of two criteria will have one answer.

For this purpose, after completing the simulations, the element that had the maximum amount of equivalent plastic strain was reported.

Then, a diagram for the highest and lowest strain versus time for that element was determined. For example, the graph for the $4 \mathrm{~mm}$ axial feeding mode (Fig. 3 ) is shown in Figure 9.

After drawing the curve, get the Microsoft Office Excel software output from the curve. Then, import that data to the MATLAB software for using the curve fitting option to earn chart's equation and twice derive from it. Figure 10 represents the second derivative of max strain graph and the data obtained from it ( $4 \mathrm{~mm}$ axial feeding mode) in MATLAB.

The time when the acceleration of the maximum strain got its maximum value $(0.006 \mathrm{~s})$ was assumed as the start of necking phenomena in the analyzed material. Finally, when the second derivative strain reaches its maximum value, consider the large strain as $\varepsilon_{\text {major }}$ and the small strain as $\varepsilon_{\text {minor }}$. 


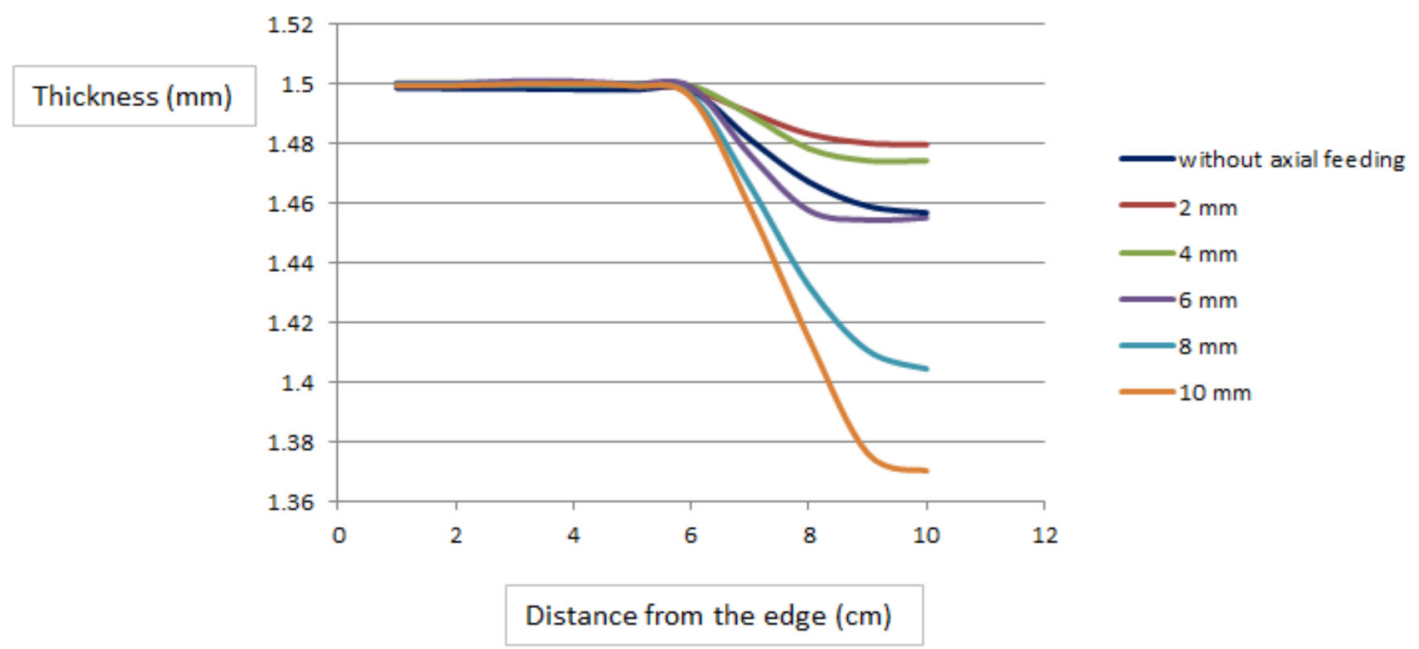

Fig. 12. Distribution of thickness.

From the combination of these two points, a point on the FLD was determined. Similarly, these steps were repeated for another loading path (Fig. 3) to obtain the other points in order to draw the FLD.

\section{Results and discussion}

In comparison, between defects, such as wrinkling and buckling, rupture is an irreversible defect in tube hydroforming [17-21]. In order to investigate the formability in the hydroforming process from the perspective of the fault rupture, numerical and experimental methods with a combination of internal pressure and axial feeding were used in this study. Internal pressure and axial feeding with different loading paths imposed on the tube which at first, the three-dimensional models simulated using finite element method. In this research, the results of the simulated hydroforming test for aluminum 7020-T6 tube were presented. The necking criteria, containing the acceleration of major and minor strains, were applied to identify the start of plastic instability in the analyzed material to construct the FLD.

The predicted FLD was compared with the experimental test results for aluminum 7020-T6 tube (Fig. 11). From Figure 11, it could be concluded that this method was in good agreement with the experimental test results for aluminum tube 7020-T6.

Figure 11 showed that there was a low difference between the results of FEM and experiment for the $\mathrm{FLD}_{0}$ (i.e., major strain in the plane strain state). Moreover, Table 2 compared the numerical predictions with the measured strains from physical experiments at the onset of necking for two different stain paths (e.g., plane strain mode and uniaxial tension mode). This difference could be due to the errors in strain measurement by the conventional "circle grid analysis" method [22-25]. Therefore, it could be deduced that the FE results were in fairly good agreement with experimental investigations. Figure 12 shows the distribution of thickness in each of the samples.

\section{Conclusions}

In this study, the hydroforming strain limit diagrams of the aluminum tube 7020-T6 were determined numerically and experimentally for the first time. The numerical method already developed for sheet materials was extended and applied to obtain the FLDs for tubular materials (aluminum tube 7020-T6). The numerical results for the FLDs were verified by comparing them with experimental tests. The numerical model was based on the acceleration of maximum principal strain or acceleration of minimum principal strain. By analyzing the two criteria large strain and small strain, it was found that both of them have a linear relationship relative to each other. So the second derivative of any of them at a time reaches its maximum value. Therefore, use of each of them has the same result in the determination of forming limit curves. This numerical criterion was used for the first time to predict the FLD of the aluminum tube 7020-T6. According to the forming limit diagrams obtained (Figure 11), it was concluded that, firstly, FLD for hydroforming process falls in left side of the line $\varepsilon_{2}=0$. (plane strain mode). And secondly, whatever the ratio between axial feeding and the internal pressure increased, the points obtained on the graph are drawn towards the negative minor strain $\left(\varepsilon_{2}\right)$. According to the thickness distribution graph in the samples (Fig. 12), it can be seen that to move from the edge of the tube to the middle of it, the thickness of the elements declined; which shows the necking phenomenon. Results from the suggested numerical simulations were in fairly good agreement with experimental investigations.

\section{Nomenclature}

$\begin{array}{ll}\text { FEM } & \text { finite element method } \\ \text { FE } & \text { finite element } \\ \text { FLD } & \text { forming limit diagram } \\ \text { FLC } & \text { forming limit curve } \\ \text { FLD }_{0} & \text { major strain in plane strain state } \\ K & \text { strength coefficient } \\ n & \text { strain hardening index } \\ \text { E } & \text { Young module }\end{array}$




\begin{tabular}{|c|c|}
\hline YS & yield strength \\
\hline$\varepsilon$ & true strain \\
\hline$r_{0}, r_{45}, r_{90}$ & $\begin{array}{l}\text { anisotropy coefficients in the different direc- } \\
\text { tions }\end{array}$ \\
\hline $\mathrm{H}, \mathrm{F}, \mathrm{G}, \mathrm{N}$ & material constants \\
\hline & engineering strain \\
\hline & major strain \\
\hline & minor strain \\
\hline EQ & equivalent plastic strain \\
\hline
\end{tabular}

The authors would like to express their deepest gratitude to Professor H. Moslemi Naeini, Dr. S.J. Hashemi and, Tarbiat Modares University (Laboratory of Metal Forming) for their help. The authors also would like to acknowledge the financial support of Iran National Science Foundation (INSF).

\section{References}

[1] R. Hashemi, G. Faraji, K. Abrinia, A.F. Dizaji, Application of the hydroforming strain- and stress-limit diagrams to predict necking in metal bellows forming process, Int. J. Adv. Manuf. Technol. 46 (2010) 551-561

[2] N. Asnafi, A. Skogsgårdh, Theoretical and experimental analysis of stroke-controlled tube hydroforming, Mater. Sci. Eng.: A 279 (2000) 95-110

[3] L.-P. Lei, J. Kim, B.-S. Kang, Bursting failure prediction in tube hydroforming processes by using rigid-plastic FEM combined with ductile fracture criterion, Int. J. Mech. Sci. 44 (2002) 1411-1428

[4] C. Zhang, L. Leotoing, D. Guines, E. Ragneau, Theoretical and numerical study of strain rate influence on AA5083 formability, J. Mater. Process. Technol. 209 (2009) 3849-3858

[5] A. Rezaee-Bazzaz, H. Noori, R. Mahmudi, Calculation of forming limit diagrams using Hill's 1993 yield criterion, Int. J. Mech. Sci. 53 (2011) 262-270

[6] K. Wang, J.E. Carsley, L. Zhang, T.B. Stoughton, J. Li, B.E. Carlson, Forming limits of an age hardenable aluminum sheet after pre-straining and annealing, Int. J. Mech. Sci. 82 (2014) 13-24

[7] W. Lee, X. Wen, A dislocation-based model of forming limit prediction in the biaxial stretching of sheet metals, Int. J. Mech. Sci. 48 (2006) 134-144

[8] R. Uppaluri, N.V. Reddy, P. Dixit, An analytical approach for the prediction of forming limit curves subjected to combined strain paths, Int. J. Mech. Sci. 53 (2011) 365-373

[9] S.P. Keeler, W.A. Backofen, Plastic instability and fracture in sheets stretched over rigid punches, ASM Trans. Q. 56 (1963) $25-48$

[10] J. Kim, B. Kang, S. Hwang, H. Park, Numerical prediction of bursting failure in tube hydroforming by the FEM considering plastic anisotropy, J. Mater. Process. Technol. 153(2004) 544-549
[11] J. Kim, S.-W. Kim, W.-J. Song, B.-S. Kang, Analytical approach to bursting in tube hydroforming using diffuse plastic instability, Int. J. Mech. Sci. 46 (2004) 1535-1547

[12] J. Kim, S.-W. Kim, W.-J. Song, B.-S. Kang, Analytical and numerical approach to prediction of forming limit in tube hydroforming, Int. J. Mech. Sci. 47 (2005) 1023-1037

[13] Y.-M. Hwang, Y.-K. Lin, H.-C. Chuang, Forming limit diagrams of tubular materials by bulge tests, J. Mater. Process. Technol. 209 (2009) 5024-5034

[14] X. Chen, Z. Lin, Z. Yu, X. Chen, S. Li, Prediction of forming limit diagram for seamed tube hydroforming based on thickness gradient criterion, in: The 8th International Conference and Workshop on Numerical Simulation of 3D Seet Metal Forming Processes (NUMISHEET 2011), 2011, pp. $653-660$

[15] S.H. Seyedkashi, V. Panahizadeh, H. Xu, S. Kim, Y.H. Moon, Process analysis of two-layered tube hydroforming with analytical and experimental verification, J. Mech. Sci. Technol. 27 (2013) 169-175

[16] R. Hill, A theory of the yielding and plastic flow of anisotropic metals, Proc. R. Soc. Lond. A: Math. Phys. Eng. Sci. 193 (1948) 281-297

[17] A. Pambhar, K. Narasimhan, Prediction of stress and strain based forming limit diagram during tube hydroforming process, Trans. Indian Inst. Metals 66 (2013) 665-669

[18] R.S. Korouyeh, H.M. Naeini, G. Liaghat, Forming limit diagram prediction of tailor-welded blank using experimental and numerical methods, J. Mater. Eng. Perform. 21 (2012) 2053-2061.

[19] A. Menhaj, M. Abbasi, M. Sedighi, M. Ketabchi, A new concept in obtaining a forming limit diagram of tailor welded blanks, J. Strain Anal. Eng. Des. 46 (2011) 740-748

[20] S.K. Paul, G. Manikandan, R.K. Verma, Prediction of entire forming limit diagram from simple tensile material properties, J. Strain Anal. Eng. Des. 48 (2013) 386-394

[21] S.K. Paul, Theoretical analysis of strain- and stress-based forming limit diagrams, J. Strain Anal. Eng. Des. 48 (2013) $177-188$

[22] N. Hedayati, R. Madoliat, R. Hashemi, Strain measurement and determining coefficient of plastic anisotropy using digital image correlation (DIC), Mech. Ind. 18 (2017) 311-320

[23] R. Hashemi, K. Abrinia, A. Assempour, H. Khakpour Nejadkhaki, A. Shahbazi Mastanabad, Forming limit diagram of tubular hydroformed parts considering the through-thickness compressive normal stress, Proc. Inst. Mech. Eng. L: J. Mater. Des. Appl. 230 (2016) 332-343

[24] S.J. Hashemi, H. Moslemi Naeini, G.H. Liaghat, H. Deilami Azodi, A. Nemati Faghir, Prediction of forming limit curve using ductile fracture criteria in hydroforming of aluminum tubes, J. Appl. Comput. Mech. 25 (2014) 11-17 (in Persian)

[25] H. Moslemi Naeini, S. Hashemi, G.H. Liaghat, M. Mohammadi, H. Deilami Azodi, Analytical prediction of limit strains and limit stresses in hydroforming of anisotropic aluminum tubes, Modares Mech. Eng. 14 (2014) 133-140 (in Persian)

Cite this article as: A. Afshar, R. Hashemi, R. Madoliat, D. Rahmatabadi, B. Hadiyan, Numerical and experimental study of bursting prediction in tube hydroforming of Al 7020-T6, Mechanics \& Industry 18, 411 (2017) 